\title{
Temporal refuges differ between human and natural top-down pressures in a subordinate carnivore
}

\author{
Rumaan Malhotra ${ }^{1}$, Samantha Lima ${ }^{2}$, and Nyeema Harris ${ }^{3}$ \\ ${ }^{1}$ University of Michigan \\ ${ }^{2}$ Purdue University \\ ${ }^{3}$ Yale University
}

November 12, 2021

\begin{abstract}
Animals exhibit variation in their space and time use across an urban-rural gradient. As the top-down influences of apex predators wane due to human-driven declines, landscape level anthropogenic pressures are rising. Human impacts can be analogous to apex predators in that humans can drive increased mortality in both prey species and carnivores, and impact communities through indirect fear effects and food subsidies. Here, we evaluate the time use of a common mesocarnivore across an urban rural gradient, and test whether it is influenced by the intensity of use of a larger carnivore. Using multiple cameratrap surveys, we compared the temporal response of a small carnivore, the raccoon (Procyon lotor), to the larger coyote (Canis latrans) at four sites across Michigan that represented a gradient of pressure from humans. We found that raccoon time use varied by site and was most unique at the rural extreme. Raccoons consistently did not shift their activity pattern in response to coyotes at the site with the highest anthropogenic pressures despite considerable interannual variation, and instead showed the stronger responses to coyotes at more rural sites. Temporal shifts were characterized by raccoons being more diurnal in areas of high coyote activity. We conclude that raccoons do partition time to avoid coyotes. Our results highlight that the variation in raccoon time use across the entirety of the urban-rural gradient needed to be considered, as anthropogenic pressures may dominate and obscure the dynamics of this interaction. In an increasingly anthropocentric world, to understand species interactions, it is imperative that we consider the entire spectrum of human pressures that it may occur within.
\end{abstract}

Temporal refuges differ between human and natural top-down pressures in a subordinate carnivore

Rumaan Malhotra ${ }^{1 *}$, Samantha Lima ${ }^{2}$ and Nyeema C. Harris ${ }^{3}$

${ }^{1}$ Ecology and Evolutionary Biology, University of Michigan 1101 N. University Ave, Ann Arbor, Michigan 48106

${ }^{2}$ Forestry and Natural Resources, Purdue University 715 W State St, West Lafayette, Indiana 47907

${ }^{3}$ Applied Wildlife Ecology Lab, School of the Environment, Yale University 195 Prospect St. New Haven, Connecticut 06511

*Correspondent: rumaanm@umich.edu

Data availability: The datasets generated during and/or analyzed during the current study are not publicly available due to ongoing research, but are available from the corresponding author on reasonable request.

\section{ABSTRACT}

Animals exhibit variation in their space and time use across an urban-rural gradient. As the top-down influences of apex predators wane due to human-driven declines, landscape level anthropogenic pressures are 
rising. Human impacts can be analogous to apex predators in that humans can drive increased mortality in both prey species and carnivores, and impact communities through indirect fear effects and food subsidies. Here, we evaluate the time use of a common mesocarnivore across an urban rural gradient, and test whether it is influenced by the intensity of use of a larger carnivore. Using multiple camera-trap surveys, we compared the temporal response of a small carnivore, the raccoon (Procyon lotor), to the larger coyote (Canis latrans) at four sites across Michigan that represented a gradient of pressure from humans. We found that raccoon time use varied by site and was most unique at the rural extreme. Raccoons consistently did not shift their activity pattern in response to coyotes at the site with the highest anthropogenic pressures despite considerable interannual variation, and instead showed the stronger responses to coyotes at more rural sites. Temporal shifts were characterized by raccoons being more diurnal in areas of high coyote activity. We conclude that raccoons do partition time to avoid coyotes. Our results highlight that the variation in raccoon time use across the entirety of the urban-rural gradient needed to be considered, as anthropogenic pressures may dominate and obscure the dynamics of this interaction. In an increasingly anthropocentric world, to understand species interactions, it is imperative that we consider the entire spectrum of human pressures that it may occur within.

Keywords: coyote, niche, partitioning, landscape of fear, Michigan, urban

\section{1 | INTRODUCTION}

Cities are a rapidly growing, emergent habitat type with projected increases to 120 million ha globally by 2030 (McDonald et al. 2018). These human pressures increasingly drive the decline of apex predators at a global scale (Ripple et al. 2014; Young et al. 2016). Similar to apex predators, humans can induce non-consumptive consequences on subordinate species through changes in space and time use (Ciuti et al. 2012; Clinchy et al. 2016). However, humans are unique in their top-down pressures in that they can exert fear effects across trophic levels, superseding hierarchies in natural systems (Smith et al. 2017; Suraci et al. 2019). The resultant heterogeneity of apex predator distribution from human pressures can induce differences in community structure as well as coexistence mechanisms within the carnivore guild (Berger 2007; Muhly et al. 2011; Moll et al. 2018). In urban areas, where spatial overlap among species are inevitable due to the limited amount of habitat available, temporal partitioning may be particularly important for species' persistence (Adams and Thibault 2006; Santos et al. 2019; Stark et al. 2020).

Urban-rural gradients provide natural experiments for comparisons of ecosystem function between natural and anthropogenic forces (McDonnell and Pickett 1990; Ellington and Gehrt 2019). Thus far, urban-rural gradients have predominantly highlighted changes in physical characteristics (e.g., body size) that can affect ecological interactions, or changes in biodiversity and species composition across taxa (Marzluff 2001; Urban et al. 2006). Although not specifically casted in an urban-rural framework, there are further evidence that humans and built structures can alter animal behavior (Van Donselaar et al. 2018; Avilés-Rodríguez and Kolbe 2019). For example, a global meta-analysis found that intensity of human pressure can drive increased nocturnality and reduce movement (Gaynor et al. 2018; Tucker et al. 2018). Altered time use due to humans can further translate into altered interspecific interactions (Lewis et al. 2015; Gallo et al. 2019). Recasting the implications of urban expansion from the primary focus of degradation to evolutionary potential occurs by considering them as novel ecosystems that have conservation value (Kowarik 2011; Seto et al. 2011; Alberti 2015). We leverage and expand upon the urban-rural gradient formed by human pressure to examine spatiotemporal dynamics between a widely distributed carnivore and a smaller sympatric competitor.

As a highly adaptive mesocarnivore, coyotes exploit a wide range of habitats and exhibit tolerance to disturbance with their diets and microbial community relating such variation across populations (Flores-Morales et al. 2019; Bekoff and Gese 2003; Colborn et al. 2020). Coyotes exemplify mesopredator release through range expansion that aligns with human caused extirpation of wolves. Though coyotes are subordinate to gray wolves where they are sympatric, they are an aggressor species for several smaller carnivores and account for high rates of mortality for some species (e.g., Vulpes velox, Vulpes macrotis ) (Berger 2007; Bekoff and Gese 2003). As a result, coyotes are commonly cited as a species that can act as both a mesopredator or an apex predator in their community, depending on the presence of the gray wolf (Prugh et al. 2009; Roemer 
et al. 2009; Colborn et al. 2020). Similarly, raccoons (Procyon lotor) exhibit tolerance to human pressures and spatially overlap through much of the coyotes North American range (Timm et al. 2017; Kays 2018). Coyote-raccoon interactions are interesting because of how widespread both species are, the size difference that should typify intraguild aggression or predation, and yet lack evidence for any sort of spatial or temporal partitioning (Gehrt and Clark 2003; Donadio and Buskirk 2006; Shedden et al. 2020). There has yet to be a study that examines the temporal dynamics of these two species across the urban-rural gradient.

Raccoons exhibit spatiotemporal variation in behavioral attributes, leading us to expect that the response of raccoons to coyotes may vary by differences in habitat and other characteristics across sites (Beasley et al. 2011). Gehrt and Prange (2007) put forth a convincing argument that raccoons and coyotes do not fit into the mesopredator release hypothesis, and there little evidence that coyotes act as a control on the abundance or spatial use of raccoons (Lesmeister et al. 2015). Telemetry studies of raccoons have found some evidence of mortality due to coyotes, but only as a rare occurrence (Gehrt and Clark 2003; Prange et al. 2003). In North Carolina, the temporal use of coyotes and raccoons largely overlapped and that raccoons overall exhibited low levels of vigilance, indicating low levels of fear from coyotes (Chitwood et al. 2020).

Given that coyotes pose some risk to raccoons based on size and sympatry, but that overall risk is low, we tested whether raccoons showed any finer scale shifts in time based on heterogeneity in coyote risk within a site. Employing a camera survey across an urban-rural gradient, we tested whether raccoon time differed between intensities of coyote spatial use. For context, we tested the variation in raccoon time use across two scales: between sites (across the urban-rural gradient) and within site, between years (interannual variation) (Figure 1), with hypotheses that: a) there raccoon time use at the most urban site would be significantly different than at the other three sites, and b) interannual variation would be more least pronounced at the urban site. Based on the strong fear effects that humans can exert on wildlife, we hypothesized that raccoon time use would not shift on the urban end of the gradient, due to activity patterns of both species avoiding peak hours of human activity. Conversely, we hypothesized that raccoons would shift in areas of intense coyote use on the rural end of the spectrum. As anthropogenic pressures increase, our knowledge of contemporary baseline ecological interactions becomes dated. Thus, it becomes essential to understand how these competitive interactions compare across landscapes with varying human pressures.

\section{2 | METHODS}

\section{1 | Study area}

We investigated raccoon temporal dynamics across differing levels of coyote activity at four sites across the state of Michigan, USA (Figure 2) which represent an urban-rural gradient.

1) The Huron Mountain Club (HMC) is a privately-owned property along the southern shore of Lake Superior, encompassing around 6,900 hectares in Marquette County, Michigan, USA. This site has a wide variety of habitats including beech-sugar maple hardwood forests, aspen dominated stands, and coniferous boreal forests. Sympatric large predators include: gray wolves, black bears (Ursus americanus ), and coyotes. Anthropogenic pressures are limited to a small, seasonally occupied area of human habitation near the north central part of the property. Hunting and fishing occur on the property, and the intensity is presumably low due to restrictive public access.

2) The University of Michigan Biological Station (UMBS), a 4,000 hectare research station and forest in Pellston County, Michigan, USA served as one of our intermediate disturbance sites. With repeated logging and fire disturbance until 1923, the secondary forest is a mix of transitional hardwood and boreal forests. Douglas and Burt lakes along the north and south, and the town of Pellston and a major highway along west and east, respectively border this study area. Large co-occurring predators include: black bears, coyotes, and coyote-wolf hybrids. We were able to distinguish the few known coyote-wolf hybrids in the area due to them having collars from a different study, which were visible in the camera trap images (Wheeldon et al. 2012). Human pressures resulted from regulated research infrastructures for climate monitoring and housing facilities with low levels concentrated seasonally during the summer. 
3) The Shiawassee National Wildlife Refuge (SNWR) is a 9,870 hectare wildlife refuge managed by the US Fish and Wildlife Service. The refuge is comprised of forested hardwood wetlands and lakeplain prairie. The city of Saginaw abuts the northern edge of the refuge and is surrounded by agricultural land for crop farming. The only large native predator present is the coyote. Anthropogenic pressures, in addition to the urban and ex-urban nature of the boundaries, are in the form of recreational visitors. Public hunting for deer and waterfowl, and furbearer trapping are permissible on the refuge in accordance with lawful seasons.

4) The Detroit Metro Parks (DMP) is a collection of greenspaces interspersed throughout southeast Michigan that is managed by the Detroit Parks and Recreation Department. We chose twenty-five of these parks that varied in size from 1.6-480 hectares, tree cover, human visitation, and degree of disturbance. Roads, buildings, or a riverine edge bound all parks. The only large native predator present is the coyote. Strong anthropogenic pressures are present in the form of the surrounding urban matrix, as well as the associated presence of humans and domestic pets across parks

\section{2 | Camera trap survey}

We deployed remotely-triggered camera traps (Reconyx@ PC 850, 850C, 900, 900C) throughout each site with camera placement and sampling design proportional to study area size (Table 1). Our study uses data from four surveys at DMP $(2017,2018,2019,2020)$, two surveys at SNWR (2016, 2018), two surveys at UMBS (2015, 2016), and four surveys at $\operatorname{HMC}(2016,2017,2018$, and 2019). We captured the heterogeneity of habitat and other environmental features to ensure ecological representation in the micro-site selection of camera traps. Camera traps were affixed to trees $>0.5 \mathrm{~m}$ diameter and placed $0.5-1.0 \mathrm{~m}$ off the ground. Site-specific placement of camera traps was determined by signs of animal activity such as game trails and scat. Camera trap settings included: high sensitivity, one-second lapse between three pictures in a trigger, and a 15 -second quiet period between triggers. Camera traps were not baited.

Image identifications were initially crowd-sourced and filtered for carnivores using a public-science program called Michigan ZoomINin combination with a consensus algorithm and expert validation (Gadsden et al. 2021). Carnivore species identifications were later sorted and confirmed by at least two independent researchers in the Applied Wildlife Ecology Lab.

2.3 Temporal activityTime stamps associated with the camera trap images were used to conduct temporal analyses. Prior to all analyses, a 30-minute quiet period was introduced for every species to account for pseudoreplication, given the tendency of some animals to remain in front of the camera trap and trigger it multiple times. Since surveys were conducted across different times of the year, we scaled times to sunrise and sunset times using thesun Times function in the 'circular' package in R (Ridout and Linkie 2009). 2.31 | Variation between sites

We first compiled all raccoon triggers from each survey within a site to have an aggregate across years of overall raccoon temporal activity at each site. We then compared raccoon temporal activity between sites using the Mardia-Watson-Wheeler (MWW) test, which is a nonparametric test of differences in the angular means between samples of circular data using the 'circular' package in $\mathrm{R}$ (version 4.1.0). When the $\mathrm{W}$ value is high it results in a significant $p$ value $(p<0.05)$, which we conclude to mean that the compared temporal activities are unique.

\subsubsection{Seasonal and yearly variation}

Our multi-site camera study allowed us to compare differences in raccoon temporal activity based on landscape level differences along an urban-rural gradient. Comparing between seasons can confound inferences from the analyses, due to different seasons potentially resulting in different detection rates (Marcus Rowcliffe et al. 2011). While we did not have identical seasonal coverage for every site, the multiple surveys at every site resulted in coverage for the entire year at every site with the exception of UMBS (Figure S1). To determine if there was consistency at sites regardless of season and year, we compared raccoon activity between each survey within each site, and then looked for broader patterns across sites.

2.3.3 Coyotes on raccoon temporal activity 
For each survey, we used a kernel density estimation for the independent coyote triggers and designated the cameras that fell within the top quantile of as 'HIGH' coyote intensity of use zones in ArcGIS Pro (version 2.3.1). We used this rather than a fixed cutoff value of expected detection rate because our sites spanned the entirety of the urban-rural gradient and expected detection rates for coyote vary depending on the composition of a site (Magle et al. 2014). Coyote triggers were checked for spatial independence using Moran's I prior to kernel density estimation. We compared raccoon temporal activity between the high coyote cameras and the rest of the site using the MWW test. For additional evidence that temporal shifts by raccoons were due to avoidance of coyotes, we then compared the overlap between coyote and raccoon time use in the two raccoon test groups from the MWW test. To do this, we calculated an overlap $(\Delta)$ coefficient of temporal activity for coyotes and raccoons within each group ('HIGH' and 'LOW' coyote intensity of use) along with $95 \%$ confidence intervals generated from 10,000 parametric bootstraps of the temporal distribution models. $\Delta$ values range from 0 to 1 , with 0 indicating completely distinct and non-overlapping temporal activity between comparison groups, and 1 indicating complete overlap. $\Delta_{1}$ was used for comparisons when one of the sample groups had less than 50 triggers; otherwise $\Delta_{4}$ was used to estimate temporal overlap (Ridout and Linkie 2009). Finally, the activity distributions were visually assessed to determine qualitative characteristics of shifts (e.g. raccoons shifting towards increased nocturnality in high coyote zones).

\section{3 | RESULTS}

We obtained 1,378 coyote and 11,136 raccoon triggers with a 30-minute quiet period across 12 surveys in 82,595 trap nights (HMC- 36,868; UMBS- 12,953; SNWR- 12,477; DMP- 20,297) from 2015-2020. Raccoons and coyotes were the most common carnivores in almost every survey, comprising $57-98 \%$ of all the carnivore triggers. In Detroit, where domestic dogs and cats comprised $35 \%$ of the triggers, coyotes were the fourth most common carnivore species after raccoons, cats, and dogs.

\subsection{Coyote relative activity}

Kernel density estimates indicated coyotes were distributed non-randomly in space (Figure 2). At DMP with heavy anthropogenic pressure (average 77 coyote triggers per camera in "HIGH" coyote zones), coyote activity was concentrated in two heavily forested parks and had few human triggers compared to the rest of the surveyed parks in Detroit. In contrast, at HMC with heavy natural apex pressure, the highest coyote activity occurred in a recreation area that contained several buildings and homes but had few overall triggers (average 3 coyote triggers per camera in "HIGH" coyote zones). Coyote activity formed distinct zones in SNWR and UMBS as well, and the location of hotspots varied by survey. Hotspots at these two sites were not associated with any discernible landscape level measures of anthropogenic pressures. Raccoon triggers were recorded within both the low and high zones of coyote activity across all sites, establishing spatial overlap between the two species

\section{2 | Variation in racoon activity between sites (Figure 1a)}

Raccoon activity at each site was unique, showing significant differences in every pairwise comparison of sites from MWW tests (Table 1). We expected raccoon activity to be the most distinct at DMP, our most urban site. Instead, we found that raccoon activity was most unique at HMC, showing considerably more use of the diurnal period (Figure 5) and significantly less overlap with the other three sites (combined confidence intervals showing 76-87\% overlap) than comparisons between UMBS, SNWR, and DMP (combined confidence intervals showing $87-96 \%$ overlap) (Figure 4 ).

\subsection{Seasonal/annual variation in raccoon activity (Figure 1c)}

Raccoon activity varied significantly by survey and year for every site with the exception of UMBS (Table 2 ). At the most urban end of the urban-rural gradient, , raccoon activity was significantly different between every year surveyed at DMP and SNWR. At UMBS, the comparison between the two years approached significance $(\mathrm{W}=5.53, p=0.063)$. While at HMC the results varied, depending on the years compared. For example, 2016/2017 and 2017/2018 comparisons showed that raccoon time use varied significantly between these years, while raccoon time use between 2018 and 2019 was similar $(\mathrm{W}=3.03, p=0.220)$. These results 
refuted our hypothesis that interannual variation would be weakest at DMP, instead showing that there is considerable variation across years at all sites.

\subsection{Coyote use on raccoon temporal activity (Figure 1b,c)}

Overall, our hypothesis for raccoon-coyote temporal interactions was largely correct, with raccoons at DMP consistently exhibiting no shift in time use relative to coyote intensity of use zones. However, there was reduced overlap between coyotes and raccoons within the high coyote zone. Results for the other sites varied by survey year (Figure 3). Below, we first present for each site the results for the comparison of raccoon activity between the high and low coyote zone. Then we provide the comparison of raccoon and coyote temporal activity within the high coyote zone (relative to the same comparison in the low coyote zone), to determine if there is evidence that a shift in raccoon activity between zones is due to temporal avoidance of coyotes.

HMC: At the most rural site, we found results for the effects of coyotes varied by survey. The 2016 and 2017 surveys exhibited no shifts, while surveys in 2018 and 2019 showed significant shifts in raccoon activity between coyote low and high zones ( $\mathrm{W}=15.12,10.02, p<0.00$ respectively) (Table 1$)$. Results were consistent even when the 2017 survey was broken up into summer and winter survey seasons since it covered an entire year, indicating no shifts in raccoon activity between coyote zones. When comparing coyote and raccoon temporal activity within each zone the 2018 survey showed some evidence of decreased temporal overlap between coyote and raccoons in the high coyote zone, while for 2019 the confidence intervals were too wide to be meaningful (Figure 3).UMBS: For both surveys, we found there were significant shifts in raccoon activity between coyote zones ( $\mathrm{W}=9.63, p<0.00$ for 2016 , and $\mathrm{W}=7.39, p=0.025$ for 2015). Both surveys showed evidence of reduced temporal overlap between coyote and raccoons in the high coyote zone.

SNWR: We found that again, results varied by survey, with two out of three surveys showing significant shifts in raccoon activity between coyote zones; $2016(\mathrm{~W}=6.08, p=0.047)$ and $2018(\mathrm{~W}=10.46, p<0.00)$ showed shifts, while in 2017 ( $\mathrm{W}=3.65, p=0.162$ ) raccoons did not shift activity. Only the 2018 survey showed evidence of reduced temporal overlap between coyotes and raccoons in the high coyote zone.

DMP: We found that raccoons exhibited no shifts in activity between coyote zones consistently across for all four years surveyed in our study. Curiously, three out of the four surveys (2018, 2019, and 2020) showed evidence of reduced overlap between raccoons and coyotes in the high coyote zone, with the difference reaching significance in the 2020 survey $\left(\Delta_{4}\right.$ CI in the high coyote zone: $0.46-0.58$ vs. low coyote zone: $\left.0.61-0.80\right)$.

\section{4 | DISCUSSION}

Behavioral adjustments in diet, spatial, and temporal use can reduce competition for resources to promote coexistence (Inouye 1978). We tested for spatial and interannual variation in the time use of raccoons across an urban-rural gradient and measured the use of temporal refuges by raccoons in the presence of coyotes across that same gradient. As expected, we found that raccoon time use varied both across the gradient and between years. More importantly, we highlight that there were consistent patterns across the urban-rural gradient in raccoon temporal response to coyotes. We found that at the most urban site (DMP), raccoons consistently did not shift their temporal activity in response to coyotes, despite significant interannual variation in raccoon activity. In contrast, all other sites showed some evidence of behavioral plasticity in raccoon time use with the intensity of coyote spatial use. These results complement other findings that: a) non-consumptive effects impact the spatial use within the carnivore guild (Newsome and Ripple 2015); and b) that non-consumptive effects (fear effects) are present within the hierarchy of the carnivore guild (Gordon et al. 2015).

Urban systems represent an extreme of human pressures, and the continuing increase in urban habitat makes understanding the unique behaviors and ecologies of wildlife in urban spaces such as Detroit, Michigan particularly important. Breck et al. (2019) found that coyotes at urban sites are bolder in comparison to their rural counterparts, which would support their role as a fear source in cities. In absence of shifts in 
raccoon activity at our DMP site, it seems that this fear effect does not extend to raccoons. Given that we did find some evidence of temporal avoidance at our other sites, a more plausible explanation is that fear of coyotes is not strong enough to elicit a shift in raccoon time use in the face of a stronger force; the most obvious in an urban system being humans and domestic dogs, as reflected by raccoons at DMP having the least diurnal activity (Figure 5) (Gaynor et al. 2018; Nix et al. 2018; Sévêque et al. 2021). Despite raccoon activity consistently being similar between zones of coyote intensity of use, raccoon activity did seem to show somewhat reduced overlap with coyote activity in the high coyote intensity of use areas. This implies that coyotes were potentially using time differently depending on how heavily used an area was by conspecifics. A plausible explanation would be intraspecific competition (Cunningham et al. 2019), or this result could more generally suggest coyotes are more plastic in their time use than raccoons in urban systems (McClennen et al. 2001). The latter would make sense; although both species are cosmopolitan, raccoons are more human tolerant than coyotes (Crooks 2002; Randa and Yunger 2006).

Surprisingly, it was not the human-dominated urban system that was the most unique in raccoon temporal use amongst the sites, but instead the more pristine HMC in northern Michigan. The overall raccoon activity pattern showed considerable use of the diurnal period during which humans tend to be most active (Figure 6 ), resulting in low overlap with other sites. HMC also showed the greatest interannual variation in raccoon response to coyotes out of the four sites, once again perhaps reflecting a lack of human impact in the form of food subsidies (Manlick and Pauli 2020). The availability of resources can modulate the strength of competition, and so annual variation in food resources could drive the avoidance response of raccoons to coyotes (Newsome et al. 2015). At the other three sites, human food waste and other human-derived subsidies likely offset years that may otherwise be relatively resource-poor for raccoons (Oro et al. 2013). Unlike UMBS and SNWR, which have nearby towns, HMC is isolated, surrounded by forest and with the few cabins on the property only seasonally occupied.

Our results highlight broad patterns in raccoon temporal use between zones of high and low coyote activity. The mechanisms that underlie these patterns require further study and a temporal shift could very likely have more nuance than simple avoidance by a subordinate carnivore. A shift in temporal use by a subordinate (as shown in our SNWR and DMP sites) might instead reflect indirect avoidance of competition with a larger competitor rather than direct avoidance of antagonistic interactions (Newsome et al. 2015). While our results indicate the response of the raccoon to be driven by a larger predator, it does not preclude an interaction between top-down and bottom-up forces, which may be important to understanding what raccoons are directly responding to across sites and survey seasons (Elmhagen and Rushton 2007). For example, resource availability, such as the abundance of small mammal prey, fluctuates with season and could be a driver of varying levels of competition between coyotes and raccoons (Batzli 1992; Fedriani et al. 2000; Neale and Sacks 2001). At an urban site (e.g., DMP), food subsidies in the form of trash could reduce seasonal variation in resource competition (Oro et al. 2013; Newsome et al. 2015). Thus, we would expect patterns of temporal use, particularly in the presence of a competitor, to vary seasonally (Sovie et al. 2019). Seasonal variation in temporal response may explain the divergent result for the 2017 SNWR survey, which occurred during the summer months. The other two surveys at the site occurred during the fall and the spring, periods which are associated with heightened resource gathering for the imminent winter, and heightened coyote aggression because of the coyote breeding season (Way 2001). Pairing dietary studies that explore the seasonal variation in coyote and raccoon diets across all sites with spatiotemporal analyses would elucidate if seasonal variation in resource availability drives resource partitioning between these species.

Though the two sites at the opposite ends of the gradient (i.e., HMC and DMP) best highlight the variation in raccoon temporal activity and temporal response to coyotes, there were site specific patterns for the entire gradient. We intended for our sampling sites to represent opposing gradients of humans and native apex predator presence, which were reflected in the amount of built structures and which carnivores were captured on camera at each site. However, given that we did not test for the effect of the relative activity of apex predators and humans, we cannot discount the possibility that factors other than top-down forces drove the urban-rural gradient we observed in our results. Sites varied in vegetative cover, topography, latitude, and distribution of resources. Though, differences in the sources of top-down forces are the most obvious 
and likely ecological factor that differs between the sites for generalist species such as raccoons and coyotes. Similar outcomes have been reported for other coyote-subordinate predator systems when compared across sites that vary in the presence of an apex predator (Shores et al. 2019).

\section{5 | CONCLUSION}

We conclude that there is evidence of temporal partitioning being used by raccoons in the presence of coyotes. On the surface, our results seemingly contradict recent works that suggest that coyotes are not an important intraguild predator for raccoons, and that raccoons thus do not partition time to avoid coyotes (Gehrt and Clark 2003; Chitwood et al. 2020). Instead, we suggest that time use shifts may be at a fine scale, and whether they are present depends on a suite of factors. Therefore for a behaviorally plastic species such as the raccoon, it is difficult to make broad conclusions about time use without considering the considerable variation across the urban-rural gradient they inhabit. Similarly for the coyote, their role as an intraguild aggressor for raccoons is not static across the urban-rural gradient. Instead, the competitive dominance of coyotes is likely dependent on the amount of human pressure and the presence of other larger competitors. Ultimately, as the human footprint on the planet continues to deepen, we need to continue reevaluating interactions across the gradient that it creates. The paradigm in conservation is also shifting to include in situconservation of species in urban habitats, rather than considering these areas solely as suboptimal sink habitats (Magle et al. 2012; Athreya et al. 2013; Mormile and Hill 2017). Studies comparing the ecological roles of species within a community between urban and natural systems are timely. Such work will prove invaluable in understanding how wildlife communities in these novel habitats differ not just in composition, but also in their function.

\section{ACKNOWLEDGMENTS}

First, we recognize implementing our camera survey and field research was conducted on lands originally belonging to the People of the Three Fires. Our work was made possible by the generous support and permission of the Detroit Metro Parks, the Shiawassee National Wildlife Refuge, the University of Michigan Biological Station, and the Huron Mountain Club. We also thank the National Science Foundation (IOS \#2140322) and the Huron Mountain Wildlife Foundation for financial support. We would like to thank the Applied Wildlife Ecology Lab at the University of Michigan for assistance with fieldwork, image classification and overall project feedback. In particular, K. Mills and S. Gámez provided valuable commentary and general edits. We also thank the countless volunteers for assistance with fieldwork including G. Gadsden, T. Carey, H. Boone and Michigan ZoomIN online community.

\section{AUTHOR CONTRIBUTIONS}

$\mathrm{NCH}$ designed the sampling protocol, $\mathrm{NCH}$ and RM formulated the idea, NCH, RM, and SL carried out fieldwork and data processing, RM carried out analyses and wrote the manuscript, NH and SL provided heavy editorial duties.

\section{REFERENCES}

Adams RA, Thibault KM. 2006. Temporal resource partitioning by bats at water holes. J Zool. 270(3):466472. doi:10.1111/j.1469-7998.2006.00152.x.

Alberti M. 2015. Eco-evolutionary dynamics in an urbanizing planet. Trends Ecol Evol. 30(2):114-126. doi:10.1016/j.tree.2014.11.007.

Athreya V, Odden M, Linnell JDC, Krishnaswamy J, Karanth U. 2013. Big Cats in Our Backyards: Persistence of Large Carnivores in a Human Dominated Landscape in India. PLOS ONE. 8(3):e57872. doi:10.1371/journal.pone.0057872.

Avilés-Rodríguez KJ, Kolbe JJ. 2019. Escape in the city: urbanization alters the escape behavior of Anolis lizards. Urban Ecosyst. 22(4):733-742. doi:10.1007/s11252-019-00845-x.

Batzli GO. 1992. Dynamics of Small Mammal Populations: A Review. In: McCullough DR, Barrett RH, 
editors. Wildlife 2001: Populations. Dordrecht: Springer Netherlands. p. 831-850. [accessed 2020 Jul 1]. https://doi.org/10.1007/978-94-011-2868-1_63.

Beasley JC, Olson ZH, Dharmarajan G, Eagan TS, Rhodes OE. 2011. Spatio-temporal variation in the demographic attributes of a generalist mesopredator. Landsc Ecol. 26(7):937-950.

Bekoff M, Gese EM. 2003. Coyote (Canis latrans). USDA Natl Wildl Res Cent-Staff Publ.:224.

Berger J. 2007. Fear, human shields and the redistribution of prey and predators in protected areas. Biol Lett. 3(6):620-623.

Breck SW, Poessel SA, Mahoney P, Young JK. 2019. The intrepid urban coyote: a comparison of bold and exploratory behavior in coyotes from urban and rural environments. Sci Rep. 9(1):1-11.

Chitwood MC, Lashley MA, Higdon SD, DePerno CS, Moorman CE. 2020. Raccoon Vigilance and Activity Patterns When Sympatric with Coyotes. Diversity. 12(9):341. doi:10.3390/d12090341.

Ciuti S, Northrup JM, Muhly TB, Simi S, Musiani M, Pitt JA, Boyce MS. 2012. Effects of humans on behaviour of wildlife exceed those of natural predators in a landscape of fear. PloS One. 7(11):e50611.

Clinchy M, Zanette LY, Roberts D, Suraci JP, Buesching CD, Newman C, Macdonald DW. 2016. Fear of the human "super predator" far exceeds the fear of large carnivores in a model mesocarnivore. Behav Ecol. $27(6): 1826-1832$.

Colborn AS, Kuntze CC, Gadsden GI, Harris NC. 2020. Spatial variation in diet-microbe associations across populations of a generalist North American carnivore. J Anim Ecol.

Crooks KR. 2002. Relative Sensitivities of Mammalian Carnivores to Habitat Fragmentation. Conserv Biol. 16(2):488-502. doi:10.1046/j.1523-1739.2002.00386.x.

Cunningham CX, Scoleri V, Johnson CN, Barmuta LA, Jones ME. 2019. Temporal partitioning of activity: rising and falling top-predator abundance triggers community-wide shifts in diel activity. Ecography. 42(12):2157-2168. doi:10.1111/ecog.04485.

Donadio E, Buskirk SW. 2006. Diet, morphology, and interspecific killing in Carnivora. Am Nat. 167(4):524536.

Ellington EH, Gehrt SD. 2019. Behavioral responses by an apex predator to urbanization. Behav Ecol. $30(3): 821-829$.

Elmhagen B, Rushton SP. 2007. Trophic control of mesopredators in terrestrial ecosystems: top-down or bottom-up? Ecol Lett. 10(3):197-206.

Fedriani JM, Fuller TK, Sauvajot RM, York EC. 2000. Competition and intraguild predation among three sympatric carnivores. Oecologia. 125(2):258-270.

Flores-Morales M, Vázquez J, Bautista A, Rodríguez-Martínez L, Monroy-Vilchis O. 2019. Response of two sympatric carnivores to human disturbances of their habitat: the bobcat and coyote. Mammal Res. 64(1):53-62.

Gallo T, Fidino M, Lehrer EW, Magle S. 2019. Urbanization alters predator-avoidance behaviours. Loison A, editor. J Anim Ecol. 88(5):793-803. doi:10.1111/1365-2656.12967.

Gaynor KM, Hojnowski CE, Carter NH, Brashares JS. 2018. The influence of human disturbance on wildlife nocturnality. Science. 360(6394):1232-1235. doi:10.1126/science.aar7121.

Gehrt SD, Clark WR. 2003. Raccoons, coyotes, and reflections on the mesopredator release hypothesis. Wildl Soc Bull 1973-2006. 31(3):836-842.

Gordon CE, Feit A, Gruber J, Letnic M. 2015. Mesopredator suppression by an apex predator alleviates the risk of predation perceived by small prey. Proc R Soc B Biol Sci. 282(1802):20142870. 
Inouye DW. 1978. Resource partitioning in bumblebees: experimental studies of foraging behavior. Ecology. 59(4):672-678.

Kays R. 2018. Canis latrans. IUCN Red List Threat Species E T3745A103893556 Doi. 10:2018-2.

Kowarik I. 2011. Novel urban ecosystems, biodiversity, and conservation. Environ Pollut. 159(8-9):19741983.

Lesmeister DB, Nielsen CK, Schauber EM, Hellgren EC. 2015. Spatial and temporal structure of a mesocarnivore guild in midwestern north America. Wildl Monogr. 191(1):1-61. doi:10.1002/wmon.1015.

Lewis JS, Bailey LL, VandeWoude S, Crooks KR. 2015. Interspecific interactions between wild felids vary across scales and levels of urbanization. Ecol Evol. 5(24):5946-5961. doi:10.1002/ece3.1812.

Magle SB, Hunt VM, Vernon M, Crooks KR. 2012. Urban wildlife research: past, present, and future. Biol Conserv. 155:23-32.

Magle SB, Simoni LS, Lehrer EW, Brown JS. 2014. Urban predator-prey association: coyote and deer distributions in the Chicago metropolitan area. Urban Ecosyst. 17(4):875-891. doi:10.1007/s11252-014$0389-5$.

Manlick PJ, Pauli JN. 2020. Human disturbance increases trophic niche overlap in terrestrial carnivore communities. Proc Natl Acad Sci. 117(43):26842-26848. doi:10.1073/pnas.2012774117.

Marcus Rowcliffe J, Carbone C, Jansen PA, Kays R, Kranstauber B. 2011. Quantifying the sensitivity of camera traps: an adapted distance sampling approach. Methods Ecol Evol. 2(5):464-476.

Marzluff JM. 2001. Worldwide urbanization and its effects on birds. In: Avian ecology and conservation in an urbanizing world. Springer. p. 19-47.

McClennen N, Wigglesworth RR, Anderson SH, Wachob DG. 2001. The Effect of Suburban and Agricultural Development on the Activity Patterns of Coyotes (Canis Latrans). Am Midl Nat. 146(1):27-36.

McDonald RI, Guneralp B, Huang C-W, Seto KC, You M. 2018. Conservation priorities to protect vertebrate endemics from global urban expansion. Biol Conserv. 224:290-299.

McDonnell MJ, Pickett ST. 1990. Ecosystem structure and function along urban-rural gradients: an unexploited opportunity for ecology. Ecology. 71(4):1232-1237.

Moll RJ, Cepek JD, Lorch PD, Dennis PM, Robison T, Millspaugh JJ, Montgomery RA. 2018. Humans and urban development mediate the sympatry of competing carnivores. Urban Ecosyst. 21(4):765-778. doi:10.1007/s11252-018-0758-6.

Mormile JE, Hill CM. 2017. Living with urban baboons: Exploring attitudes and their implications for local baboon conservation and management in Knysna, South Africa. Hum Dimens Wildl. 22(2):99-109.

Muhly TB, Semeniuk C, Massolo A, Hickman L, Musiani M. 2011. Human activity helps prey win the predator-prey space race. PLoS One. 6(3):e17050.

Neale JC, Sacks BN. 2001. Food habits and space use of gray foxes in relation to sympatric coyotes and bobcats. Can J Zool. 79(10):1794-1800.

Newsome TM, Dellinger JA, Pavey CR, Ripple WJ, Shores CR, Wirsing AJ, Dickman CR. 2015. The ecological effects of providing resource subsidies to predators. Glob Ecol Biogeogr. 24(1):1-11. doi:10.1111/geb.12236.

Newsome TM, Ripple WJ. 2015. A continental scale trophic cascade from wolves through coyotes to foxes. J Anim Ecol. 84(1):49-59. 
Nix JH, Howell RG, Hall LK, McMillan BR. 2018. The influence of periodic increases of human activity on crepuscular and nocturnal mammals: Testing the weekend effect. Behav Processes. 146:16-21. doi:10.1016/j.beproc.2017.11.002.

Oro D, Genovart M, Tavecchia G, Fowler MS, Martinez-Abrain A. 2013. Ecological and evolutionary implications of food subsidies from humans. Ecol Lett. 16(12):1501-1514.

Prange S, Gehrt SD, Wiggers EP. 2003. Demographic Factors Contributing to High Raccoon Densities in Urban Landscapes. J Wildl Manag. 67(2):324-333. doi:10.2307/3802774.

Prugh LR, Stoner CJ, Epps CW, Bean WT, Ripple WJ, Laliberte AS, Brashares JS. 2009. The rise of the mesopredator. Bioscience. 59(9):779-791.

Randa LA, Yunger JA. 2006. Carnivore occurrence along an urban-rural gradient: a landscape-level analysis. J Mammal. 87(6):1154-1164. doi:10.1644/05-MAMM-A-224R2.1.

Ridout MS, Linkie M. 2009. Estimating overlap of daily activity patterns from camera trap data. J Agric Biol Environ Stat. 14(3):322-337. doi:10.1198/jabes.2009.08038.

Ripple WJ, Estes JA, Beschta RL, Wilmers CC, Ritchie EG, Hebblewhite M, Berger J, Elmhagen B, Letnic M, Nelson MP, et al. 2014. Status and Ecological Effects of the World's Largest Carnivores. Science. 343(6167):1241484-1241484. doi:10.1126/science.1241484.

Roemer GW, Gompper ME, Van Valkenburgh B. 2009. The Ecological Role of the Mammalian Mesocarnivore. BioScience. 59(2):165-173. doi:10.1525/bio.2009.59.2.9.

Santos F, Carbone C, Wearn OR, Rowcliffe JM, Espinosa S, Lima MGM, Ahumada JA, Goncalves ALS, Trevelin LC, Alvarez-Loayza P, et al. 2019. Prey availability and temporal partitioning modulate felid coexistence in Neotropical forests. PloS One. 14(3):e0213671.

Schuette P, Wagner AP, Wagner ME, Creel S. 2013. Occupancy patterns and niche partitioning within a diverse carnivore community exposed to anthropogenic pressures. Biol Conserv. 158:301-312.

Seto KC, Fragkias M, Guneralp B, Reilly MK. 2011. A meta-analysis of global urban land expansion. PloS One. 6(8):e23777.

Seveque A, Gentle LK, Vicente Lopez-Bao J, Yarnell RW, Uzal A. 2021. Impact of human disturbance on temporal partitioning within carnivore communities. Mammal Rev. doi:10.1111/mam.12265. [accessed 2021 Oct 5]. https://onlinelibrary.wiley.com/doi/abs/10.1111/mam.12265.

Shedden JM, Bucklin DM, Quinn NM, Stapp P. 2020. Do Coyotes Eat Mesocarnivores in Southern California? A Molecular Genetic Analysis. Proc Vertebr Pest Conf. 29(29). [accessed 2021 Oct 15]. https://escholarship.org/uc/item/1023p03m.

Shores CR, Dellinger JA, Newkirk ES, Kachel SM, Wirsing AJ. 2019. Mesopredators change temporal activity in response to a recolonizing apex predator. Behav Ecol. 30(5):1324-1335. doi:10.1093/beheco/arz080.

Smith JA, Suraci JP, Clinchy M, Crawford A, Roberts D, Zanette LY, Wilmers CC. 2017. Fear of the human 'super predator'reduces feeding time in large carnivores. Proc R Soc B Biol Sci. 284(1857):20170433.

Sovie AR, Greene DU, Frock CF, Potash AD, McCleery RA. 2019. Ephemeral temporal partitioning may facilitate coexistence in competing species. Anim Behav. 150:87-96.

Stark JR, Aiello-Lammens M, Grigione MM. 2020. The effects of urbanization on carnivores in the New York metropolitan area. Urban Ecosyst. 23(2):215-225. doi:10.1007/s11252-019-00923-0.

Suraci JP, Clinchy M, Zanette LY, Wilmers CC. 2019. Fear of humans as apex predators has landscape-scale impacts from mountain lions to mice. Ecol Lett. 22(10):1578-1586. 
Timm R, Cuaron A, Reid F, Helgen K, Gonzalez-Maya J. 2017. Procyon lotor. The IUCN Red List of Threatened Species 2016: e. T41686A45216638.

Tucker MA, Bohning-Gaese K, Fagan WF, Fryxell JM, Moorter BV, Alberts SC, Ali AH, Allen AM, Attias N, Avgar T, et al. 2018. Moving in the Anthropocene: Global reductions in terrestrial mammalian movements. Science. 359(6374):466-469. doi:10.1126/science.aam9712.

Urban MC, Skelly DK, Burchsted D, Price W, Lowry S. 2006. Stream communities across a rural-urban landscape gradient. Divers Distrib. 12(4):337-350.

Van Donselaar JL, Atma JL, Kruyf ZA, LaCroix HN, Proppe DS. 2018. Urbanization alters fear behavior in black-capped chickadees. Urban Ecosyst. 21(6):1043-1051. doi:10.1007/s11252-018-0783-5.

Way JG, Auger PJ, Ortega IM, Strauss EG. 2016. Eastern coyote denning behavior in an anthropogenic environment. Northeast Wildlife. 56:18-30.

Young HS, McCauley DJ, Galetti M, Dirzo R. 2016. Patterns, Causes, and Consequences of Anthropocene Defaunation. Annu Rev Ecol Evol Syst. 47(1):333-358. doi:10.1146/annurev-ecolsys-112414-054142.

\section{FIGURE LEGENDS}

Fig. 1 The three comparisons considered within our study: a) Raccoon temporal activity was compared between sites; b) raccoon activity was compared between years, and across zones of coyote intensity of use within each site; c) the results from the within site comparisons of raccoon time use in response to coyotes were compared across sites.

Fig. 2 Kernel density (KD) heatmaps of coyote spatial use at the four study sites based on the number of independent coyote detections at each camera. From north to south, the Huron Mountain Club (HMC), the University of Michigan Biological Station (UMBS), the Shiawassee National Wildlife Refuge (SNWR), and the Detroit Metroparks (DMP). These represent a single year at each of the sites; hotspots in coyote detections varied by year, and KD maps were generated for each survey.

Fig. 3 Mean temporal overlap $\left(\Delta_{\text {temporal }}\right)$ between raccoons and coyotes in high and low spatial zones of coyote activity with $95 \%$ confidence intervals.

Fig. 4 Mean temporal overlap ( $\Delta$ Overlap) in raccoon activity conducted pairwise between sites with $95 \%$ confidence intervals. The letters correspond with each site $(\mathrm{H}=\mathrm{HMC}, \mathrm{U}=\mathrm{UMBS}, \mathrm{S}=\mathrm{SNWR}, \mathrm{D}=\mathrm{DMP})$, with the site it was compared to on the axis below. The differences between sites in each pairwise comparison were significant (using the MWW test).

Fig. 5 Raccoon activity across all four sites. Time use of raccoons was summed for all surveys within a site.

\section{TABLE LEGENDS}

Table 1 . Temporal overlap $(\Delta)$ coefficients and $95 \%$ confidence intervals for raccoon and coyote activity in low and high coyote zones within each camera survey in Michigan. Trap nights equals the total number of cameras multiplied by the number of nights each camera was active. Mardia-Watson-Wheeler test results comparing raccoon activity between the top quantile and the bottom three quantiles of raccoon activity for each survey are contained in the last two columns, where $\mathrm{W}$ is the test statistic (approximately Chi-sq distributed), and $p$ value are included.

Table 2 . Mardia-Watson-Wheeler test results comparing raccoon activity at each site between each survey year. $\mathrm{W}$ is the test statistic (approximately Chi-sq distributed), and associated degrees of freedom and $p$ value are included.

\section{TABLES}

Table 1. 


\begin{tabular}{|c|c|c|c|c|c|}
\hline \multirow{2}{*}{$\begin{array}{l}\text { Survey period } \\
\text { Mav-Aug }\end{array}$} & \multicolumn{2}{|c|}{ Site/Year } & \multicolumn{3}{|c|}{ Trapnights (n) } \\
\hline & & HMC'19 & \multicolumn{3}{|l|}{3445} \\
\hline Jun-Aug & \multicolumn{2}{|c|}{ HMC'18 } & \multicolumn{3}{|l|}{8338} \\
\hline Jul-Jun JJunJunJUNJunJunJun'18 & \multicolumn{2}{|c|}{ HMC'17 } & \multicolumn{3}{|l|}{10874} \\
\hline Jun-Oct & \multicolumn{2}{|c|}{ HMC'16 } & \multicolumn{3}{|l|}{14211} \\
\hline Jul-Nov & & UMBS'16 & \multicolumn{3}{|l|}{8586} \\
\hline Oct-Dec & & UMBS'15 & \multicolumn{3}{|l|}{4367} \\
\hline Sep-Dec & & SNWR'18 & \multicolumn{3}{|l|}{3862} \\
\hline May-Aug & & SNWR'17 & \multicolumn{3}{|l|}{3076} \\
\hline Feb-May & & SNWR'16 & \multicolumn{3}{|l|}{5539} \\
\hline Jan-Sep & & DMP'20 & \multicolumn{3}{|l|}{11713} \\
\hline Oct-Feb & & DMP'18 & \multicolumn{3}{|l|}{4487} \\
\hline Nov-Mar & & DMP'17 & \multicolumn{3}{|l|}{4097} \\
\hline \multicolumn{6}{|l|}{ Table 2.} \\
\hline & Years & Site & W & $\mathrm{df}$ & pvalue \\
\hline & 19 vs 18 & $\mathrm{HMC}$ & 3.030 & 2 & 0.220 \\
\hline & 18 vs 17 & $\mathrm{HMC}$ & 22.99 & 2 & 0.000 \\
\hline & 17 vs 16 & $\mathrm{HMC}$ & 6.77 & 2 & 0.034 \\
\hline & 16 vs 15 & UMBS & 5.533 & 2 & 0.063 \\
\hline & 18 vs 17 & SNWR & 35.319 & 2 & 0.000 \\
\hline & 17 vs 16 & SNWR & 26.202 & 2 & 0.000 \\
\hline & 20 vs 18 & DMP & 7.948 & 2 & 0.018 \\
\hline & 18 vs 17 & DMP & 9.884 & 2 & 0.007 \\
\hline
\end{tabular}

Fig. 1 


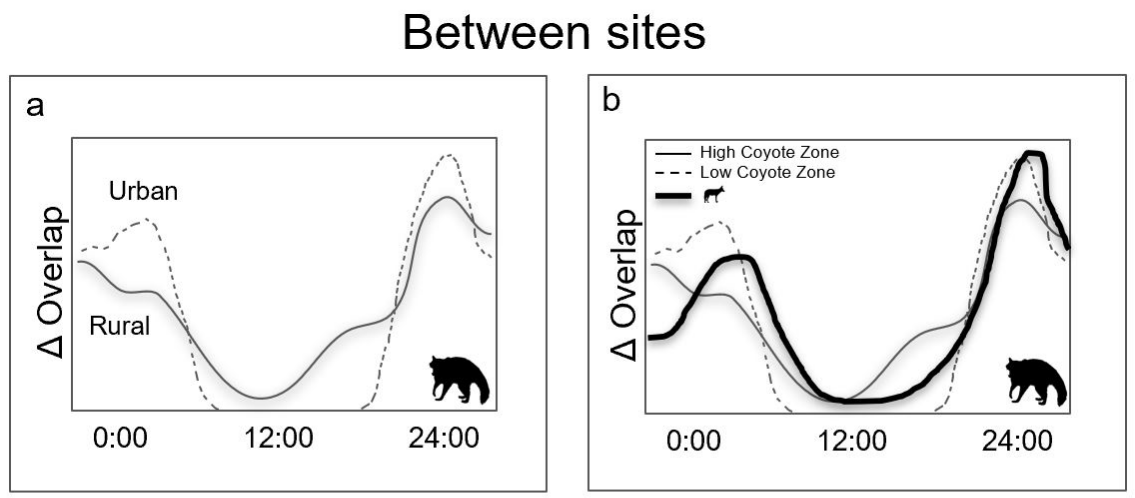

Within site

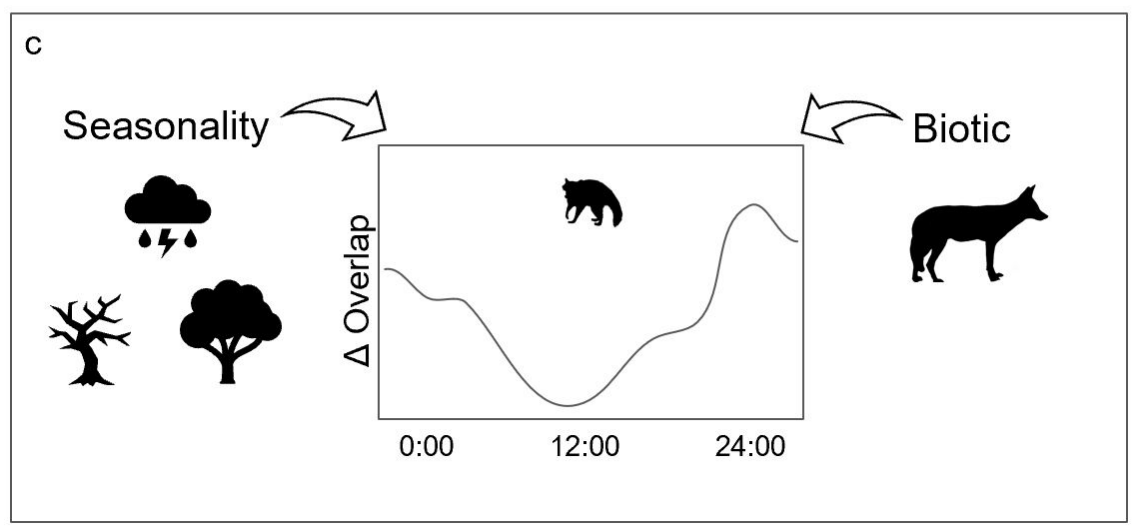




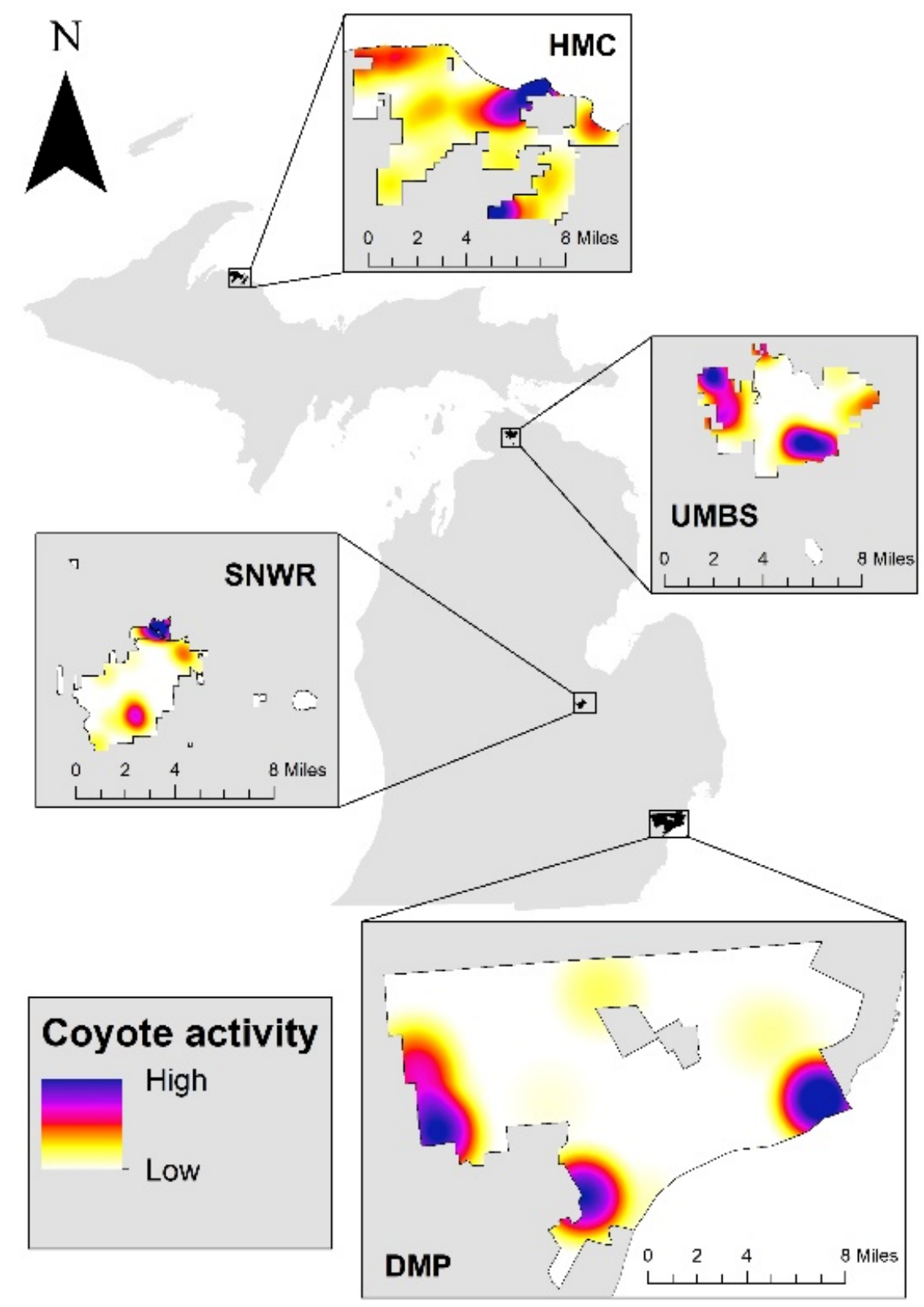

Fig. 2 


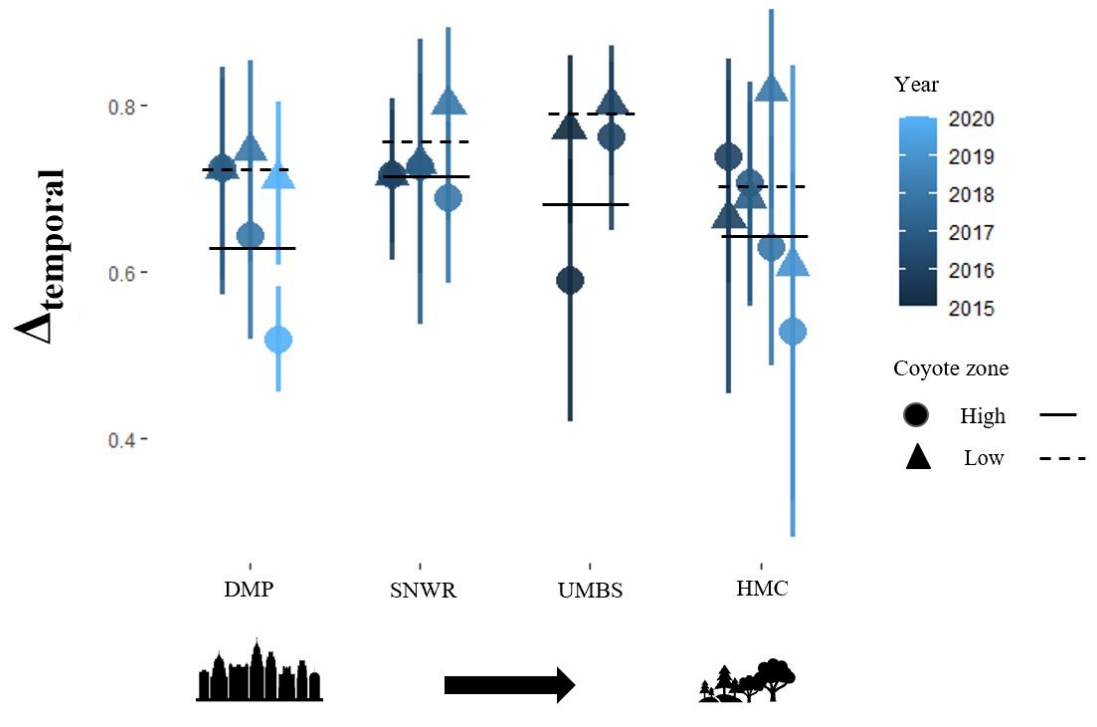

Fig. 3

Fig. 4

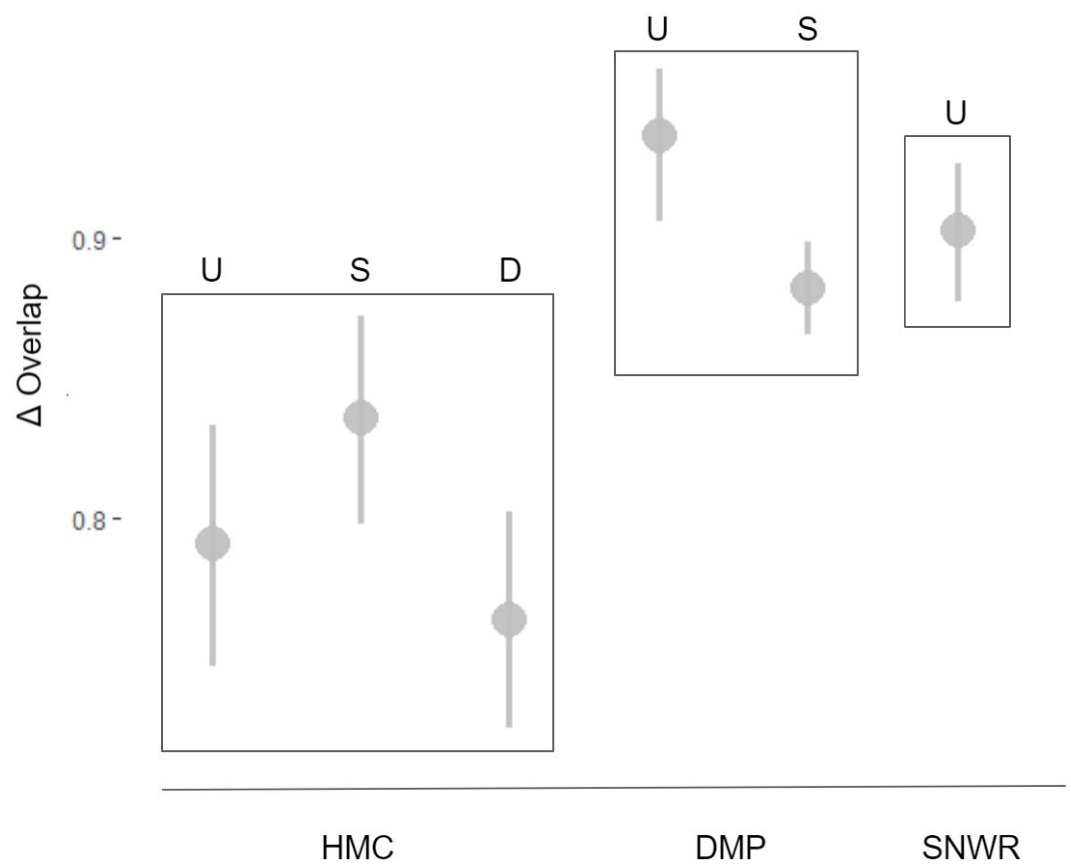

Fig. 5 


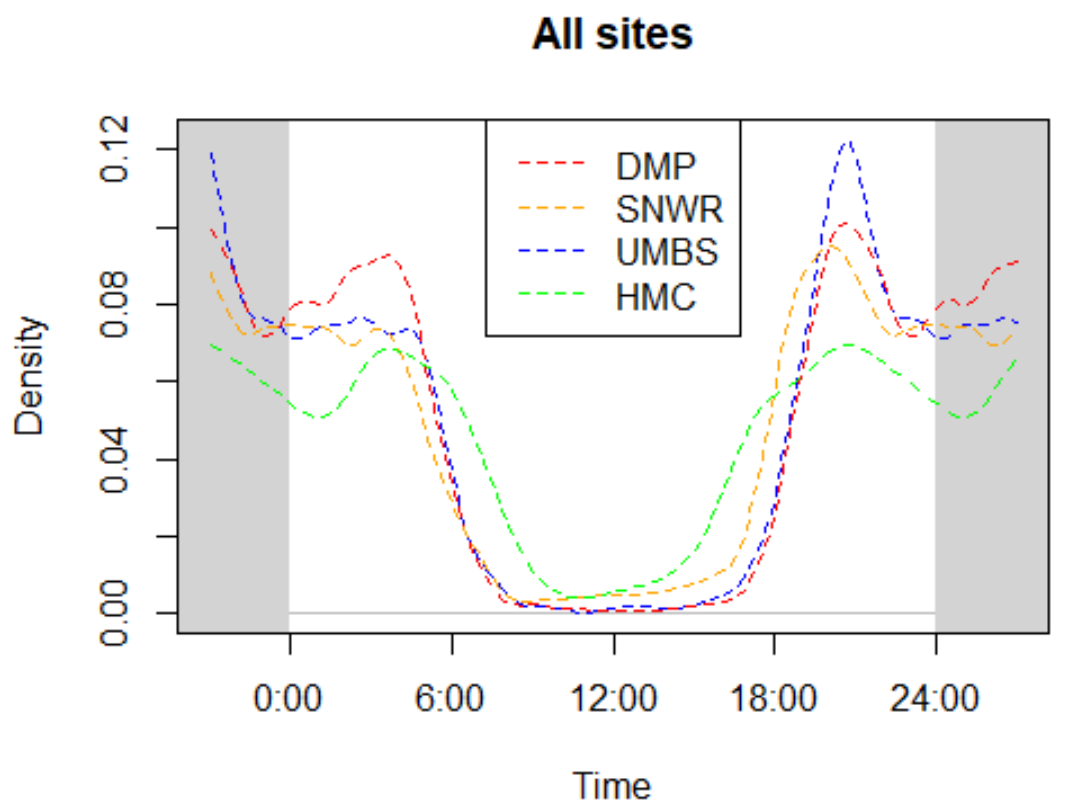

Fig. S1 Concurrent surveys between sites used in analysis. At least two surveys were conducted at each site between 2015 and 2020. Surveys run chronologically from right to left; those surveys that have two survey periods within a year are surveys that were run through December, into the following year (e.g. HMC 2017 ran from July 2017 through May 2018).

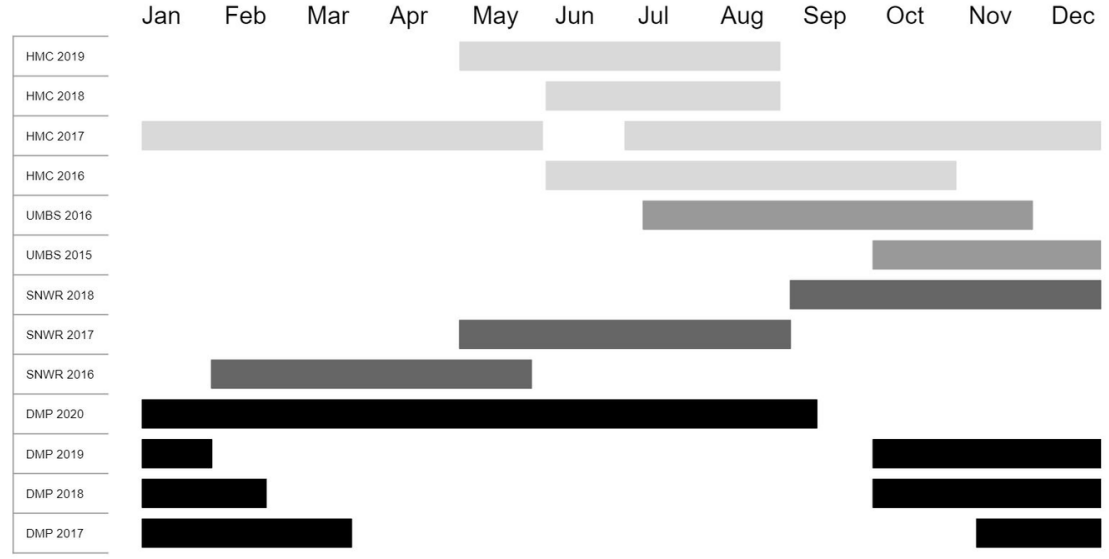

\section{Fig.S1}

Table S1. Raccoon activity between sites using Mardia-Watson-Wheeler test. W is the test statistic (approximately Chi-sq distributed), and associated degrees of freedom and $p$ value are included. Temporal overlap $(\Delta)$ coefficients and $95 \%$ confidence intervals are also included to assess the overlap in activity patterns between sites. Raccoon activity at each site was based off the aggregated raccoon triggers for all 
surveys with that site.

\begin{tabular}{|c|c|c|c|c|c|}
\hline Site Comparison & $\mathbf{W}$ & $\mathrm{df}$ & pvalue & $\Delta_{o \varepsilon}$ & $\Delta\left({ }^{(")} \mathrm{I}\right)$ \\
\hline HMC vs UMBS & 50.001 & 2 & 0.00 & 0.79 & $0.75-0.83$ \\
\hline HMC vs SNWR & 40.358 & 2 & 0.00 & 0.84 & $0.79-0.87$ \\
\hline HMC vs DMP & 80.085 & 2 & 0.00 & 0.76 & $0.72-0.80$ \\
\hline UMBS vs SNWR & 9.654 & 2 & 0.01 & 0.90 & $0.88-0.93$ \\
\hline UMBS vs DMP & 9.54 & 2 & 0.01 & 0.94 & $0.91-0.96$ \\
\hline SNWR vs DMP & 63.218 & 2 & 0.00 & 0.88 & $0.87-0.90$ \\
\hline
\end{tabular}

